\title{
Improvement of Interfacial Shear Strength of Mendong Fiber (Fimbristylis globulosa) Reinforced Epoxy Composite Using the AC Electric Fields
}

\author{
Heru Suryanto, ${ }^{1}$ Eko Marsyahyo, ${ }^{2}$ Yudy Surya Irawan, ${ }^{3}$ Rudy Soenoko, ${ }^{3}$ and Aminudin ${ }^{1}$ \\ ${ }^{1}$ Mechanical Engineering Department, State University of Malang, Jalan Semarang 5, Malang, East Java 65145, Indonesia \\ ${ }^{2}$ Mechanical Engineering Department, National Institute of Technology, Jalan Sigura-Gura, Malang, East Java 65145, Indonesia \\ ${ }^{3}$ Mechanical Engineering Department, University of Brawijaya, Jalan Veteran, Malang, East Java 65145, Indonesia \\ Correspondence should be addressed to Heru Suryanto; heru.suryanto.ft@um.ac.id
}

Received 6 February 2015; Revised 23 April 2015; Accepted 14 May 2015

Academic Editor: Adriana Gregorova

Copyright ( 2015 Heru Suryanto et al. This is an open access article distributed under the Creative Commons Attribution License, which permits unrestricted use, distribution, and reproduction in any medium, provided the original work is properly cited.

\begin{abstract}
The effects of the AC electric field treatment on the interfacial shear strength of mendong fiber-reinforced epoxy composites were investigated. For this purpose, the epoxy (DGEBA) with a cycloaliphatic amine curing agent was treated by the AC electric field during the curing process. The heat generated during the epoxy polymerization process was monitored. Structure of the epoxy was studied by X-ray diffraction, Fourier transform infrared spectroscopy (FTIR), and Scanning Electron Microscope, respectively. The interfacial shear strength (IFSS) was also measured using a single fiber pull-out test. XRD analyzes indicated that the treatment of AC electric fields was able to form a crystalline phase of epoxy. IFSS of the mendong fiber-reinforced epoxy composites was optimum increased by $38 \%$ in the AC electric fields treatment of $750 \mathrm{~V} / \mathrm{cm}$.
\end{abstract}

\section{Introduction}

Natural fibers have been offering many advantages in the recent years. The benefits of natural fiber composites that compared to composites with synthetic fiber reinforcement are low price, low density, being easily separated, being abundantly available, being renewable, being biodegradable, and having no health hazard $[1,2]$. Several alternatives to fiber sources of crop as agricultural byproducts including wheat straw [3], rice straw [4], switch grass [5], indian grass [6], napier grass [7], and mendong grass [8] have been used to produce cellulose fibers. Some of such fibers have applied in the polymer composite.

Diglycidyl ether of bisphenol A (DGEBA) is the most common epoxy resin type. It is used extensively in industry due to its fluidity and ease of processing. It possesses many desirable properties such as high chemical and corrosion resistance, excellent mechanical and thermal properties, adhesion to various substrates, low shrinkage upon cure, and good electrical insulating properties [9]. DGEBA was able to be processed under a variety of conditions and widely used as structural and composite materials [10].

The physical properties of epoxy depend on the extent of cure, which depends on the curing conditions and time and temperature of cure [11]. The curing process is a process where the polymerization reaction occurs which determines the morphology of the matrix resin and properties of structures [12]. It was conducted using an autoclave [13], radiation of ultraviolet [14], microwave [15], and electron beam [16]. However, that curing process uses a heat energy that causes thermal residual stress. This stress was decreasing in the flexural strength of the epoxy composite material by $20 \%$ [17], the interfacial toughness by $40 \%$ [18], fatigue life by $10 \%$ [19], and delamination [17]. For this reason, efforts are necessary to minimize the use of heat in the curing process, such as by applying an electric field during the curing process.

When the epoxy was used as composite matrix, the changes of epoxy properties would influence its composites. The change in the nature of the epoxy is strongly influenced by the structure and orientation of the molecular chains. It 
may be done by adding a functional polymer matrix [20] like both plasticizers and rubber [21], modifying the structure through molecular orientation by using shear flow, such as injection molding and extrusion, or using the external field such as electric field, magnetic field, and a combination of both [22]. The presence of the DC electric current and electromagnetic fields cause an increase in the impact strength of carbon fiber composite polymer by $24.7 \%$ and $43.6 \%$ for DC current of $25 \mathrm{~A}$ and $50 \mathrm{~A}$, respectively [23], and also the interaction of static load and electromagnetic fields able to decrease in defflection of the reinforced carbon composite plate by $60 \%$ in electromagnetic infuluence of 1 Tesla. It indicates that the bending stiffness of the reinforced carbon composite plate was increasing [24]. However, the presence of DC electric field is very high in the composite glass/epoxy cause of aging that causes delamination and debonding between the glass fiber and epoxy matrix [25]. In the composite compaction process, the electric field exposure with AC and DC source is capable of modifying the epoxy resin in which the physical stability and strength of the epoxy are increased by $100 \%$ and $50 \%$ in presence of AC and DC fields, respectively [10]. The external electric field causes the movement of electrons due to the intrinsic dipole arrangement of opposite charge [26] and setting the orientation of the molecule [27]. In polar molecules, the polarity of the electric field can improve the surface and lead to increased adhesion properties of the polymer interface PET/gelatin [28]. The electric field is also able to convert hydrogen bonds [29] and capable of forming a covalent bond as the molecular interactions of polar and non polar bond [30]. The change of polarization also occurs in the dielectric material due to the presence of an electric field [31] and the presence of free-moving electrons at the interface fiber/matrix (interfacial polarization) that arises in the process of making a composite [32]. In epoxy curing, nanolamellar microstructure was changed due to orientation of the microgel particle before gelation process occurs so that the epoxy surface topography becomes more rugged than no oriented epoxy [33]. These physical changes will affect the interfacial shear strength (IFSS) of composites. Therefore, this study was done to show the effects of exposure to AC electric fields during the curing process on IFSS of the mendong fiberepoxy matrix.

\section{Material and Methods}

2.1. Material. The research material was mendong fibers. Samples were obtained from the cultivation land in the district of Wajak, Malang, East Java, Indonesia. Samples were selected in the harvest age of 5-6 months, and the straw length was $1-1.2 \mathrm{~m}$. The chemical properties contents of mendong fibers were $72.14 \%$ cellulose, $20.2 \%$ hemicellulose, $3.44 \%$ lignin, $4.2 \%$ extractive compound, and moisture of $4.2 \%-$ $5.2 \%$. Mendong fiber has tensile strength, stiffness modulus, and specific strength of $452 \mathrm{MPa}, 17 \mathrm{GPa}$, and $507 \mathrm{kN} \cdot \mathrm{m} / \mathrm{kg}$, respectively [8].

The polymer matrix was diglycidyl ether of bisphenol-A (DGEBA) (brand name Eposchon, PT. Justus Kimia Raya,

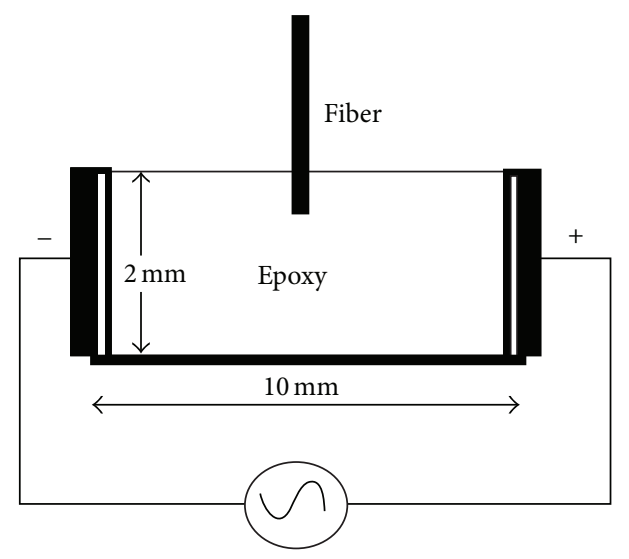

Figure 1: Treatment of AC electric fields during epoxy curing.

Surabaya, Indonesia) with an epoxy equivalent to $189 \pm 5$. The curing agent was a modified cycloaliphatic amine containing mainly 3-aminomethyl-3,5,5-trimethylcyclohexylamine (brand name EPH 555 from PT. Justus Kimia Raya, Surabaya, Indonesia) with an amine hydrogen equivalent weight of 86 and viscosity 0,5-1 Poise at room temperature. Resin and curing agent were carefully and homogeneously mixed at a ratio of $2: 1$.

2.2. Fiber Extraction. Mendong fibers were extracted mechanically. The wet mendong straw was cut off $60 \mathrm{~cm}$ long from the base, and the next piece to the top was removed. Mendong straw was repeatedly pounded and then cleaned using water. Then, fibers were soaked in water for a week. Mendong fibers were retrieved, cleaned, and allowed to dry up in ambient temperature. Mendong fibers were mercerized by immersion into $5 \% \mathrm{NaOH}$ solution for 2 hours at ambient temperature and then rinsed using an aquadest for five times, dried, and kept in plastic wrap and put in a dry box with humidity of $40 \%$ [8].

2.3. AC Electric Fields Treatment. Treatment of an AC electric field to pull-out tests was performed during the curing process of the epoxy from the liquid to solid. This process is conducted by making a plastic mold with the size of $100 \times$ $10 \times 2 \mathrm{~mm}$. Then, ten pieces of fibers with a length of $30 \mathrm{~mm}$ were prepared on a ruler that was attached on a digital height gauge ( $0.02 \mathrm{~mm}$ resolution). Furthermore, epoxy was mixed with the curing agent in the ratio $2: 1$ and then stirred and poured into molds. Fibers move down slowly into the epoxy liquid in the mold until the depth of the fiber embedded in an epoxy matrix reaches $200 \mu \mathrm{m}$ and is recorded as embedded fiber length, as shown in Figure 1. The exposure of AC electric field was conducted between a pair of electrodes by frequency $1 \mathrm{kHz}$ and varying electric fields of $250 \mathrm{~V} / \mathrm{cm}, 500 \mathrm{~V} / \mathrm{cm}$, $750 \mathrm{~V} / \mathrm{cm}$, and $1000 \mathrm{~V} / \mathrm{cm}$ for 2 hours. After the epoxy was solid, the epoxy that contains the fiber is cut with a razor blade to the size of $5 \times 5 \times 2 \mathrm{~mm}^{3}$. merization. $20 \mathrm{~g}$ epoxy was mixed with $10 \mathrm{~g}$ curing agents 
in beaker glass and then stirred at $150 \mathrm{rpm}$ for $30 \mathrm{~s} .15 \mathrm{~g}$ of this mixture was poured into tube with diameter of $25 \mathrm{~mm}$ and then exposed to the $\mathrm{AC}$ electric fields by frequency $1 \mathrm{kHz}$ and varying AC electric fields of $250 \mathrm{~V} / \mathrm{cm}, 500 \mathrm{~V} / \mathrm{cm}$, $750 \mathrm{~V} / \mathrm{cm}$, and $1000 \mathrm{~V} / \mathrm{cm}$. The heat was generated while the epoxy polymerization was measured by a temperature sensor of LM15 type (resolution $0.01^{\circ} \mathrm{C}$, National Semiconductor, USA) that linked to microcontrol and computer. The sensor was placed in the middle of epoxy tube and temperature was measured for $110 \mathrm{~min}$.

2.5. X-Ray Diffraction Analysis. X-ray diffraction studies were performed under room conditions, using PanAnalytical type X-Pert Pro Diffractometer system with $\mathrm{CuK} \alpha$ radiation $(\lambda=1.54 \AA)$. Flat sample was used for X-ray diffraction analysis. The diffracted intensity of $\mathrm{CuK} \alpha$ radiation was recorded between $5^{\circ}$ and $80^{\circ}$ ( $2 \theta$ angle range) at $40 \mathrm{kV}$ and $30 \mathrm{~mA}$.

2.6. FTIR Analysis. Infrared spectra were recorded in Shimadzu IR Prestige-21, FTIR spectrometer. Epoxy sample was in the form of flat with $0.1 \mathrm{~mm}$ thick. IR spectra were recorded in the spectral range of $4000-400 \mathrm{~cm}^{-1}$ with resolution of $2 \mathrm{~cm}^{-1}$.

2.7. Fiber Pull-Out Test. The single fiber pull-out test was conducted for determining IFSS of the fiber-matrix interface. Holder pull-out test samples were made by gluing fiber on the thick paper with a distance of $6 \mathrm{~mm}$ from the epoxy matrix as shown in Figure 2. Pull-out tests were carried out by using a fiber tensile testing device with force gauge $5 \mathrm{~N}$ with $1 \mathrm{mN}$ resolution. Tensile test was performed with a crosshead speed of $3.5 \mathrm{~mm} / \mathrm{min}$ at ambient temperature. Each treatment will take 10 samples of the test.

2.8. Morphological Studies. The morphological structure of the epoxy was observed using FEI, Inspect-S50 type Scanning Electron Microscope (SEM). All specimens were sputtered with a $10 \mathrm{~nm}$ layer of gold before the SEM observations.

\section{Result and Discussion}

3.1. Temperature Profile during Curing Process. The curing process starts from mixing epoxy resin and hardener to begin a chemical reaction that transforms the epoxy liquid into a solid. This process involves a complex process as different chemical reactions and an exothermic chemical reaction. In general, both gelation and vitrification are the most significant phenomena of this process [34]. Profile of temperature during the curing process of epoxy in the AC electric fields was shown in Figure 3.

From the measurements of the temperature during the curing process of epoxy, that exposed by the AC electric field shows the total exothermic heat of chemical reaction was lower than epoxy without the treatment. The polymerization has strongly influenced the molecular response to the AC electric fields [35]. Meir et al. [36] demonstrate that an external electric field can act as an accessory catalyst or an inhibitor

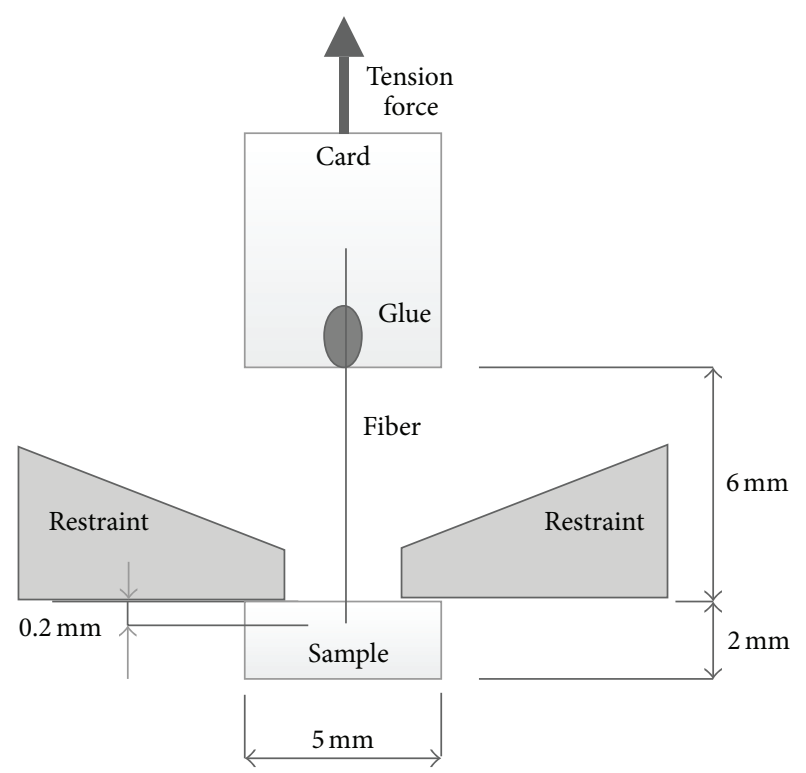

Figure 2: Single fiber pull-out test.

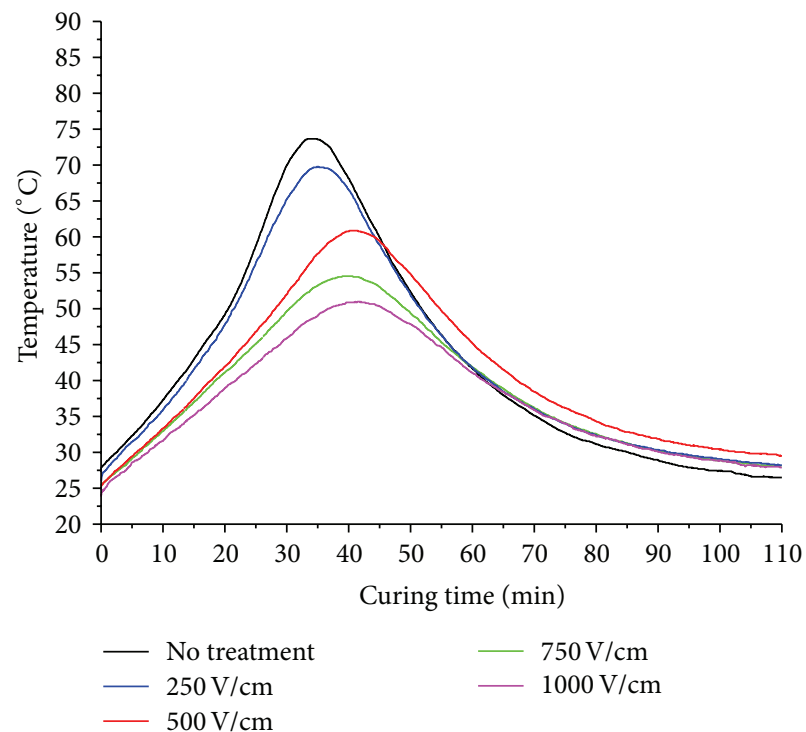

FIGURE 3: Temperature profiles at the center point of $3 \mathrm{~cm}$ diameter of the tube.

for organic reactions like Diels-Alders reaction. When the electric fields were oriented along the "reaction axis," the barrier of the reactions is lowered by a significant amount. Simply flipping the electric fields' direction has the opposite effect, and the electric fields act as an inhibitor. Additionally, an electric field oriented perpendicular to the "reaction axis" in the direction of the individual molecule dipoles can change the endothermic or exothermic selectivity. In this case, treatments of $\mathrm{AC}$ electric field in curing process were able to reduce the occurrence of the epoxy polymerization reaction. It was indicated by a reduction in the temperature of exothermic reaction of the epoxy polymerization. The reaction temperature is $73.7,69.7,60.9,54.5$, and $51^{\circ} \mathrm{C}$ for the $\mathrm{AC}$ 


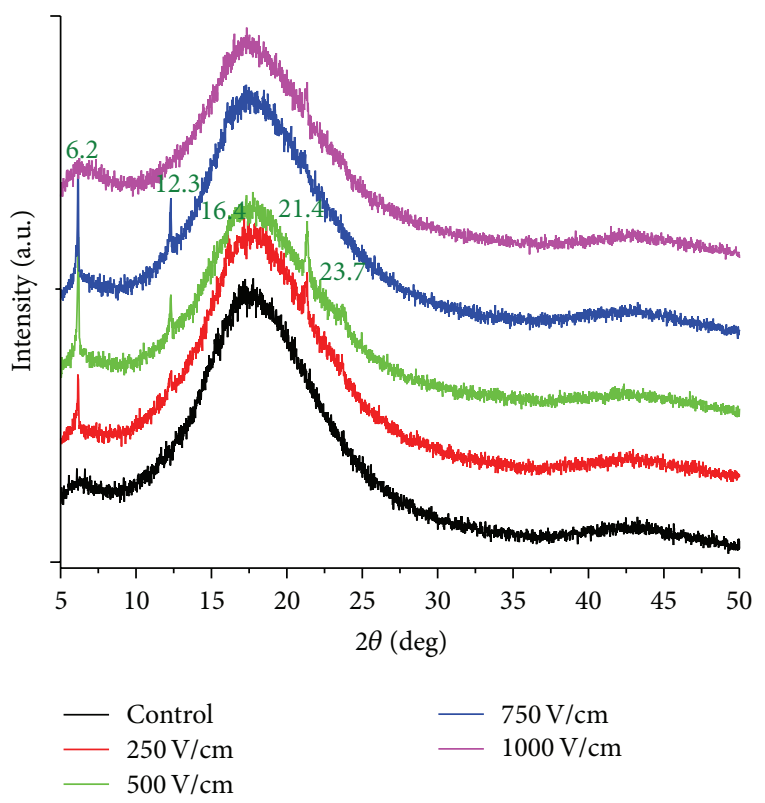

FIgURE 4: Diffractogram of epoxy cured in AC electric fields.

electric fields $0 \mathrm{~V} / \mathrm{cm}$ (nontreatment), $250 \mathrm{~V} / \mathrm{cm}, 500 \mathrm{~V} / \mathrm{cm}$, $750 \mathrm{~V} / \mathrm{cm}$, and $1000 \mathrm{~V} / \mathrm{cm}$, respectively. Genge [37] mentions that the reduction in the polymerization reaction was due to inhibition of the initiation of the polymerization process by AC electric field within a certain range $(1500-4000 \mathrm{~V} / \mathrm{cm})$ and due to the reduced reactivity of the monomers to produce a polymerization reaction.

Besides physical treatment, inhibition of polymerization reaction of epoxy (oxirane reaction) can be done by adding a stabilizer such as caprolactam, salicylamide, N,Ndimethylformamide, and monooctadecenyl urea with the aim of lowering the excessive polymerization which can reduce the flexibility of epoxy [38] and adding a plasticizer. The decreasing on cure temperature produces a linear polymer chains, low cross-link density and decreased in shrinkage and crack propagation [39]. This causes the epoxy to become more ductile [40].

3.2. XRD Analysis. It is commonly understood that amorphous chain segments can have some long-range order. XRD is used for the conformation analysis of chain segment ordering. The $2 \theta$ scans for four different treatments on epoxy samples are shown in Figure 4. There are significant peaks that can be attributed to crystalline phase. The treatment of AC electric fields of 250,500 , and $750 \mathrm{~V} / \mathrm{cm}$ results in a new crystal phase peak by the $2 \theta$ angle: $6.2^{\circ}, 12.3^{\circ}, 16.4^{\circ}, 21.4^{\circ}$, and $23.7^{\circ}$. Peak intensity was increased to treatment of AC electric fields $750 \mathrm{~V} / \mathrm{cm}$. It indicates that epoxy structure was undergo orientation. However, by higher field strength $(1000 \mathrm{~V} / \mathrm{cm})$, peak intensity was disappearing at an angle $2 \theta=21.4^{\circ}$. It indicates that epoxy crystal has not formed yet at higher electric fields.

Inhibition of the polymerization reaction in epoxy (Figure 3) was resulting in a reduction of branching chain structure, and the chains were regularly organized by electric fields. The portion of the polymer chain which was regularly organized should be noted as a crystalline structure [41]. The electric field can increase the nucleation and growth of crystals [42]. In the macromolecules, the influence of the electric field on the crystal growth can occur in the field strength $10^{4}-10^{6} \mathrm{~V} / \mathrm{m}$ and could also occur in an electric field with a value less than the specified threshold. It was also explained that the electric field can decrease or increase the free energy formation of phases, depending on the initial and final phase of the dielectric constant. When the final phase of the dielectric constant was lower than the initial phase, an increase in the nucleation process for the free energy of formation of a new phase was decreased, and vice versa $[43,44]$.

The change in the intensity of the crystal peak signifies that the crystal phase segments reoriented by electric fields. The peak of the crystal increases proportionally to the increment in the electric field strength. Li and Kessler [45] show that the liquid crystalline thermoset was able to be oriented by a magnetic field at the crystal peaks at angles $2 \theta$ $=5^{\circ}$. The arrangement of polymer chains due to the work of the external field causes changes in the polymer chain axis and the microstructure [46]. The chain arrangement is a result of the orientation of the dipole matrix derived from the movement of polar group matrix [47]. This orientation of the crystal structure produces anisotropic materials which differing in physical and mechanical properties.

The molecular orientation of a structure is strongly influenced by the dipole moment contained in the structure and the activity of the dipole moment is greatly influenced by the frequency of the applied electric field. At the low frequencies, all dipoles were oriented and permittivity material will be increased, but at the high frequency, the dipole is not able to follow the electric field so that orientation does not happen [48]. This orientation process that occurs lasted until the structure is locked due to the cross-link reaction that takes place simultaneously with the orientation process [49].

Basically, the dipole moments in a hydrogen bond can generate the electric field strength in the core. The electric field gradient at the nucleus also appears from the orientation of the dipole moment of the molecules around it. So, the change of the dipole moment will alter the degree of relationship of proton transfer and the change in dipole moment of the hydrogen bonds can change the resonant frequency of the bond [50]. The proton/electron transfer can form a bond which forms a supramolecular motif (synthons). This motif can undergo molecular fragments that affect the crystallinity of the material [51]. Partial crystallization of macromolecules, based on bisphenol $\mathrm{A}$, has been done by annealing techniques, the addition of organic solvents, and the use of supercritical $\mathrm{CO}_{2}$ and steam and electrostatic field. In a nanofiber manufacturing, the phenomenon of partial crystallization of macromolecules has been observed to improve their mechanical properties [52].

3.3. FTIR Analysis. FTIR was used to study the changes in the epoxy peaks which occur when the curing reaction took 


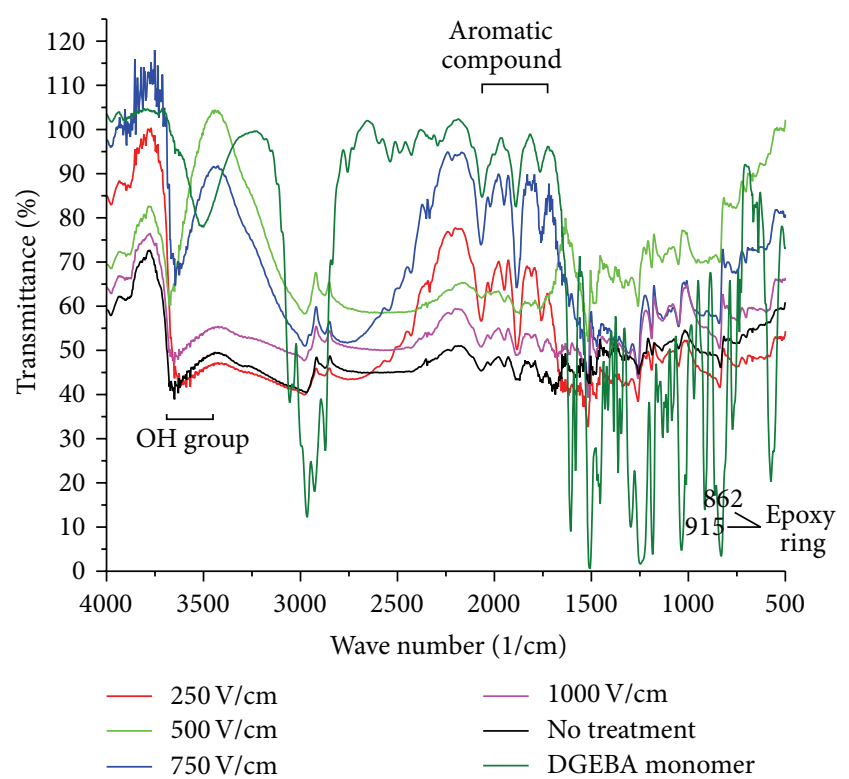

FIGURE 5: FTIR spectra of epoxy cured in AC electric fields.

place. The spectrum of epoxy system exposed to the AC electric field during curing process is shown in Figure 5.

The prominent features that occurred during polymerization were the decreasing of the epoxy ring at $915 \mathrm{~cm}^{-1}$ and $862 \mathrm{~cm}^{-1}$ [53]. In the treatment of the AC electric field of both $500 \mathrm{~V} / \mathrm{cm}$ and $750 \mathrm{~V} / \mathrm{cm}$, there is a striking change in absorption intensity, as shown in Figure 5. A simple aromatic compound in DGEBA monomer is observed between 2000 and $1700 \mathrm{~cm}^{-1}$ [54]. In these treatments, these peaks were rather similar to DGEBA monomer. It means that some of the monomers were inhibited to react with hardener. It was also observed in peaks of $3400-3600 \mathrm{~cm}^{-1}$ which shows $\mathrm{OH}$ absorbance is low. It means the formation of the secondary amine and the hydroxyl groups during cure was decreased.

Based on the results of the FTIR and XRD analysis, epoxy structure was crystallized and oriented. Crystalline epoxy was similar to solidification of pure DGEBA that forms a crystalline phase [55]. The occurrence of a molecule orientation is caused by interactions between molecules in a polymer chain. Interaction of both polar and nonpolar molecules was occurring due to fluctuations in the density distribution of electrons/protons in the molecule. It depended on the molecule polarizability, and the change of polarization depends on temperature and direction of the orientation of the polar molecule [56].

3.4. Surface Morphology of Epoxy. The exposure of AC electric field with a frequency of $1 \mathrm{kHz}$ was able to change the epoxy surface topography (Figure 6). Epoxy with no treatment has a smooth surface (Figure 6(a)). On exposure to the AC electric field of $250 \mathrm{~V} / \mathrm{cm}$, a change in the structure is shown by the presence of the needle-shaped epoxy phase (dendrites) on the surface (Figure 6(b)). In the exposure of the AC electric field (500 and $750 \mathrm{~V} / \mathrm{cm}$ ), epoxy phase was becoming more widespread in certain regions that have relatively the same direction (Figures 6(c) and 6(d)). In the AC electric field exposure of $1000 \mathrm{~V} / \mathrm{cm}$, the phase changes into a wider structure with phase dendrites at its widest side (Figure 6(e)). These surface morphology changes are caused by both the crystallization and the reorientation of epoxy structure in certain areas until the structure has been locked because the solidification process is complete. It is shown that the peak emergence in the diffractogram is due to the exposure of AC electric fields by several diffraction angles (Figure 4).

The intense exposure of AC electric fields was able to change the electrical properties and microstructure of the polymer. The effects of electric fields exposure to epoxy cause the surface topography to become rugged. Roughness was suspected because of the oriented interplane. These changes result from ionization instability associated with the generation of currents resulting from electrostatic $[33,57]$.

3.5. Interfacial Shear Strength (IFSS). Figure 7 shows the interface strength values at varying AC electric field treatment on epoxy during the curing process.

The interface shear strength (IFSS) is an indicator of the effectiveness of the bond between the fibers with the matrix. Epoxy without treatment using the AC electric fields during curing process has IFSS of mendong fiber-epoxy matrix by 11.1 MPa. After the AC electric field exposure, the IFSS of mendong fiber-epoxy matrix was increased to $12 \mathrm{MPa}$, 14.2 $\mathrm{MPa}, 15.2 \mathrm{MPa}$, and 14.1 MPa with percentage of $8 \%, 28 \%$, $38 \%$, and $27 \%$ by AC electric fields exposure of $250,500,750$, and $1000 \mathrm{~V} / \mathrm{cm}$, respectively. The IFSS mendong fiber-epoxy matrix was optimum through treatment of the AC electric field of $750 \mathrm{~V} / \mathrm{cm}$ with increasing value of $38 \%$.

The increasing of the IFSS was related to the change of the epoxy cross-link during AC electric field treatment. The high cross-link density makes epoxy brittle and weak in adhesion strength [21]. Improved interface shear stress has been associated with changes in the nature of the matrix due to a decrease in cross-link density of epoxy. This reduction is indicated by the exothermic heat generated during the process of lower cross-link (Figure 3). A lightly cross-linked amine cured epoxy polymer to the fiber surface creates a beneficial interphase resulting in a substantial increase in adhesion of fiber-matrix [58]. Cross-link density reduction causes an epoxy more ductile, tough [59], and flexible [21].

The significant changes in the material properties can be achieved through the formation of molecular arrangement producing a heterogeneous morphology caused by the presence a crystal phase [60]. In this study, formation of crystal phase was improving the IFSS of mendong fiberepoxy matrix. Formed crystal in this system was functioning as a particle that toughens the epoxy. This improvement mechanism was known as second phase-toughened system. It was already applied using plasticizer [21] and rubber [61] and rigid crystalline particle [62]. Crystalline phase in polymer induces changes in mechanical properties (effective Young's modulus, residual stresses, practical adhesion, durability, etc.) [63]. The increase of crystallinity also can improve the efficiency of stress transfer at the interface [64] and 


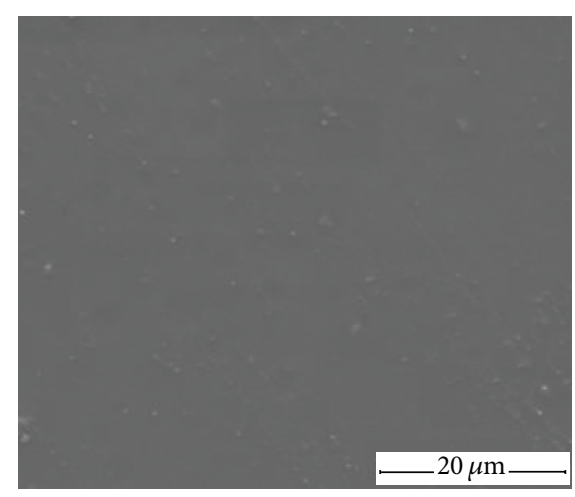

(a)

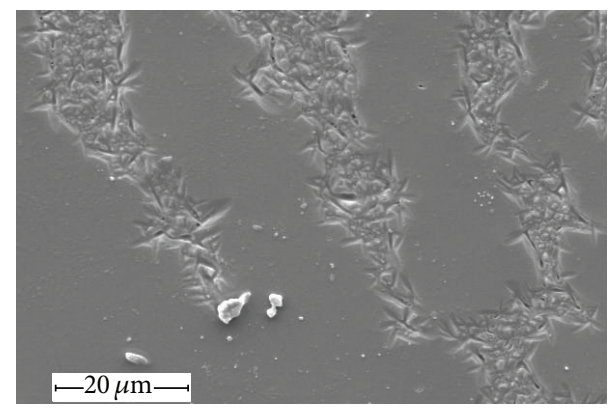

(c)

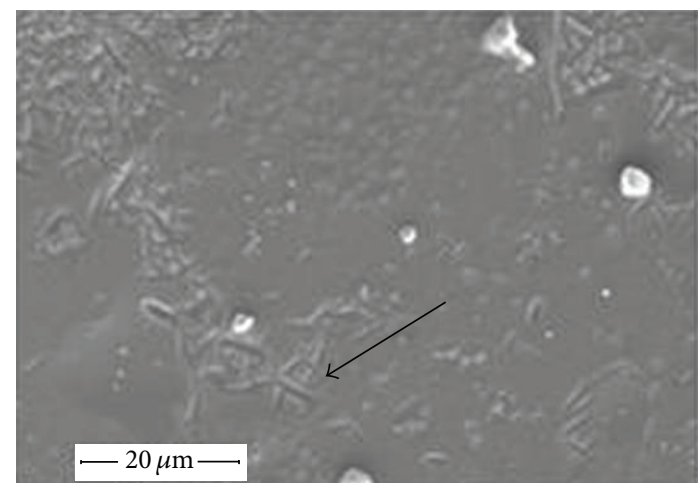

(b)

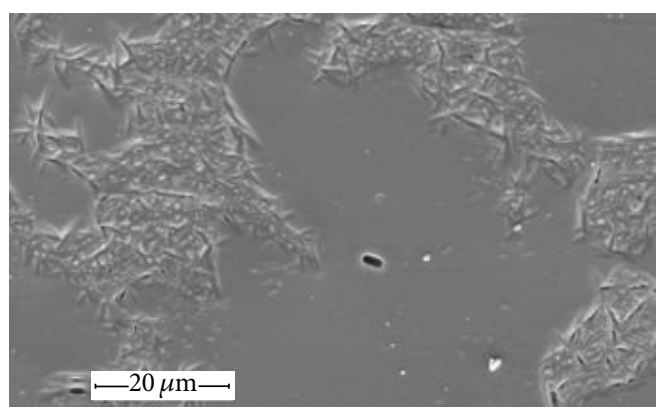

(d)

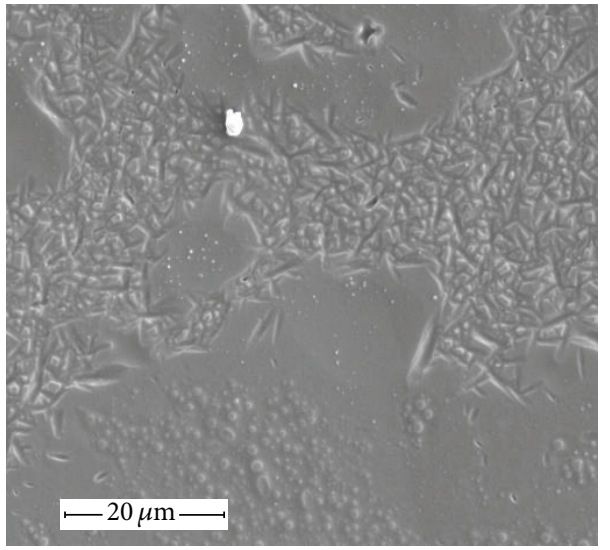

(e)

FIGURE 6: Surface morphology of epoxy exposure by AC electric fields with the following AC electric fields strength: $0 \mathrm{~V} / \mathrm{cm}$ (no treatment) (a); $250 \mathrm{~V} / \mathrm{cm}(\mathrm{b}) ; 500 \mathrm{~V} / \mathrm{cm} \mathrm{(c);750} \mathrm{V/cm} \mathrm{(d);} 1000 \mathrm{~V} / \mathrm{cm}(\mathrm{e})$.

strengthen the bond adhesion as in polypropylene lamination process [65]. The crystals in polymer have functioned as a cross-link bond and act as filler in the polymer. The change in crystallinity of the matrix causes changes in shear modulus. The higher the shear modulus of the matrix, the greater the IFSS [66].

Figure 8(a) shows the fiber pull-out specimens and Figures 8(b) and 8(c) show the hole in the epoxy block after pull-out test.

Overview of the mendong fiber embedded in epoxy after a pull-out test showed that the mendong fiber embedded in epoxy without electric field treatment (Figure 8(b)) exhibited a rough surface in some parts of the epoxy surface rupture.
It indicates that the properties of the epoxy showed a brittle fracture. At the mendong fiber embedded in epoxy with AC electric field treatment (Figure 8(c)), the surface rupture exhibited a smooth surface in some parts of the epoxy surface rupture, and epoxy had undergone stretching. It indicates that the properties of the epoxy tend to be ductile. The effect of fiber as a reinforcing will be the maximum when it uses a matrix that is more ductile [67]. As shown in Figure 3, the treatment of AC electric fields on epoxy during a curing process was able to reduce the cross-link density. In DGEBA systems, the lower the cross-link densities, the lower the shrinkage. The total shrinkage is smaller because the number of covalent bonds formed per unit volume is smaller [68] 


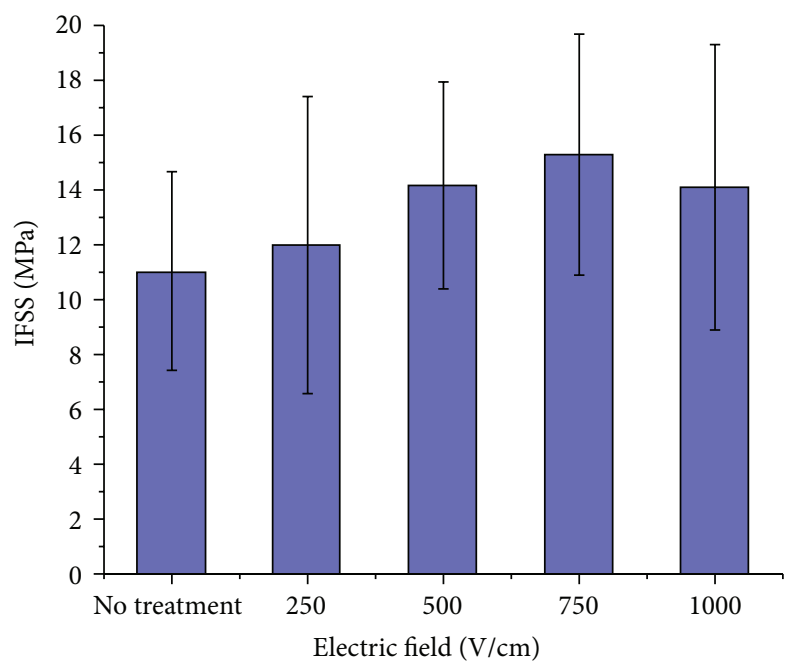

Figure 7: The influence of the AC electric fields treatment on the IFSS between mendong fiber and epoxy thermoset $(N=10)$.

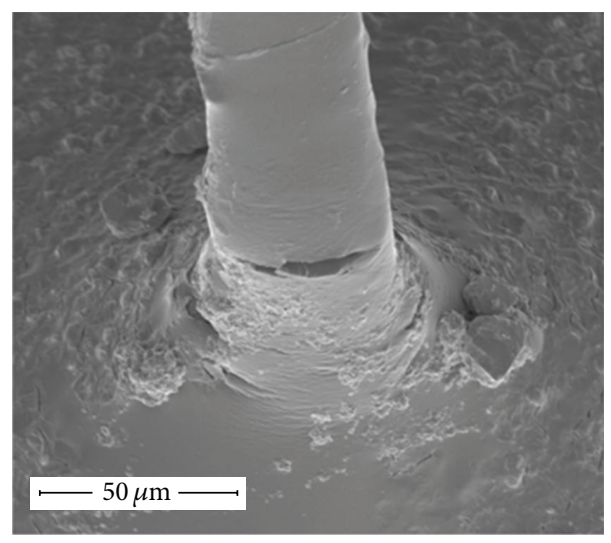

(a)

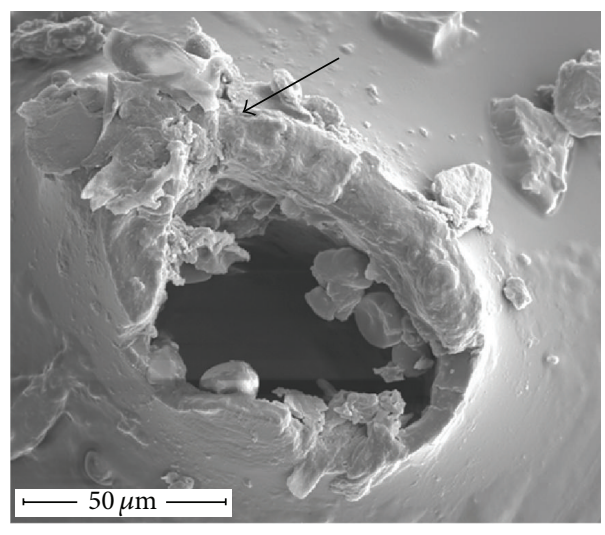

(b)

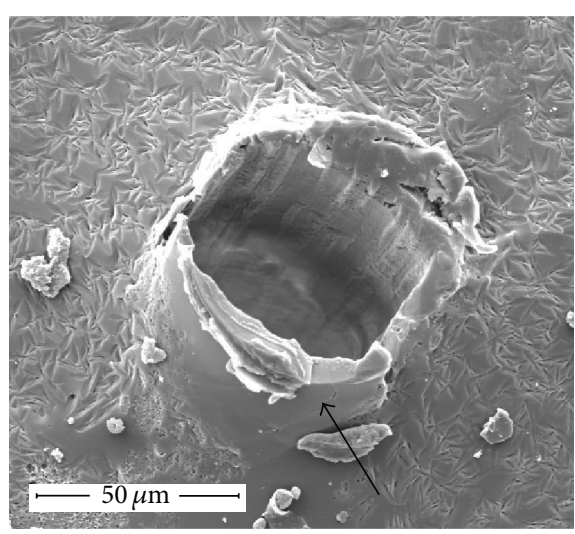

(c)

FIGURE 8: SEM micrographs of a mendong fiber pull-out specimen. (a) Fiber embedded in epoxy, (b) cavity in nontreated epoxy after pull-out test, and (c) cavity in treated epoxy using AC electric fields $750 \mathrm{~V} / \mathrm{cm}$ after pull-out test.

and the lower volume shrinkage implied the higher adhesion strength of resin since the internal stress was minimized $[69,70]$. Besides that, the lower cross-linked epoxy resins result the better mobility of the polymer chain which makes the epoxy matrix more ductile compared with high cross-link epoxy [40].

\section{Conclusion}

The present work reports the effects of AC electric field treatment during the curing process to interface strength of mendong fiber-reinforced epoxy composites. The materials have been characterized by X-ray diffraction studies, FTIR 
spectroscopy, single fiber pull-out test, and SEM microscopies. The application of AC electric fields during the curing process of epoxy decreases the exotherm reaction temperature from $73.7^{\circ} \mathrm{C}$ to $51^{\circ} \mathrm{C}$ for nontreatment to electric field treatment of $1000 \mathrm{~V} / \mathrm{cm}$, respectively, and functional group of epoxy had undergone a polarization in the presence of electric fields. The crystalline phase in epoxy structure was formed and shown at diffractogram peak by the $2 \theta$ angle: $6.2^{\circ}$, $12.3^{\circ}, 16.4^{\circ}, 21.4^{\circ}$, and $23.7^{\circ}$ with the presence of the needleshaped epoxy phase in the epoxy structure morphology. As a result, the interface strength of the mendong fiber-reinforced epoxy composites was optimum increased by $38 \%$ in the AC electric fields treatment of $750 \mathrm{~V} / \mathrm{cm}$. Finally, it is worth noting that further research is still required to evaluate the effect of frequency and waveform of AC electric fields in curing epoxy to develop nonthermal curing methods for better interface fiber-matrix strength.

\section{Conflict of Interests}

The authors declare that there is no conflict of interests regarding the publication of this paper.

\section{Acknowledgments}

This work was supported by the Ministry of Research, Technology and Higher Education, Indonesia, through the Fundamental Research Program with Contract no. 9.4.3/UN32.14/LT/2015.

\section{References}

[1] X. Li, L. G. Tabil, and S. Panigrahi, "Chemical treatments of natural fiber for use in natural fiber-reinforced composites: a review," Journal of Polymers and the Environment, vol. 15, no. 1, pp. 25-33, 2007.

[2] Q. Mu, C. Wei, and S. Feng, "Studies on mechanical properties of sisal fiber/phenol formaldehyde resin in-situ composites," Polymer Composites, vol. 30, no. 2, pp. 131-137, 2009.

[3] N. Reddy and Y. Yang, "Preparation and characterization of long natural cellulose fibers from wheat straw," Journal of Agricultural and Food Chemistry, vol. 55, no. 21, pp. 8570-8575, 2007.

[4] N. Reddy and Y. Yang, "Properties of high-quality long natural cellulose fibers from rice straw," Journal of Agricultural and Food Chemistry, vol. 54, no. 21, pp. 8077-8081, 2006.

[5] N. Reddy and Y. Yang, "Natural cellulose fibers from switchgrass with tensile properties similar to cotton and linen," Biotechnology and Bioengineering, vol. 97, no. 5, pp. 1021-1027, 2007.

[6] W. Liu, A. K. Mohanty, P. Askeland, L. T. Drzal, and M. Misra, "Influence of fiber surface treatment on properties of Indian grass fiber reinforced soy protein based biocomposites," Polymer, vol. 45, no. 22, pp. 7589-7596, 2004.

[7] K. O. Reddy, C. U. Maheswari, D. J. P. Reddy, and A. V. Rajulu, "Thermal properties of Napier grass fibers," Materials Letters, vol. 63, no. 27, pp. 2390-2392, 2009.

[8] H. Suryanto, E. Marsyahyo, Y. S. Irawan, and R. Soenoko, "Effect of alkali treatment on crystalline structure of cellulose fiber from mendong (Fimbristylis globulosa) straw," Key Engineering Materials, vol. 594-595, pp. 720-724, 2014.
[9] J. P. B. Souza and J. M. Reis, "Thermal behavior of DGEBA (Diglycidyl Ether of Bisphenol A) adhesives and its influence on the strength of joints," Applied Adhesion Science, vol. 1, no. 1, article 6, 10 pages, 2013.

[10] G. Babich and G. Cherevashchenko, "Modification of the epoxy resin by use of electric field," in Proceedings of the PEGASUS/AIAA Student Conference.

[11] M. S. Islam, K. L. Pickering, and N. J. Foreman, "Curing kinetics and effects of fibre surface treatment and curing parameters on the interfacial and tensile properties of hemp/epoxy composites," Journal of Adhesion Science and Technology, vol. 23, no. 16, pp. 2085-2107, 2009.

[12] J. Chen and M. Hojjati, "Microdielectric analysis and curing kinetics of an epoxy resin system," Polymer Engineering \& Science, vol. 47, no. 2, pp. 150-158, 2007.

[13] M. M. Thomas, B. Joseph, and J. L. Kardos, "Experimental characterization of autoclave-cured glass-epoxy composite laminates: cure cycle effects upon thickness, void content, and related phenomena," Polymer Composites, vol. 18, no. 3, pp. 283299, 1997.

[14] A. Endruweit, M. S. Johnson, and A. C. Long, "Curing of composite components by ultraviolet radiation: a review," Polymer Composites, vol. 27, no. 2, pp. 119-128, 2006.

[15] R. Yusoff, M. K. Aroua, A. Nesbitt, and R. J. Day, "Curing of polymeric composites using microwave Resin Transfer Moulding (RTM)," Journal of Engineering Science and Technology, vol. 2, no. 2, pp. 151-163, 2007.

[16] J. Raghavan and M. R. Baillie, "Electron beam curing of polymer composites," Polymer Composites, vol. 21, no. 4, pp. 619-629, 2000.

[17] S. S. Kim, H. Murayama, K. Kageyama, K. Uzawa, and M. Kanai, "Study on the curing process for carbon/epoxy composites to reduce thermal residual stress," Composites Part A: Applied Science and Manufacturing, vol. 43, no. 8, pp. 1197-1202, 2012.

[18] J. A. Nairn, C. Liu, D. Mendels, and S. Zhandarov, "Fracture mechanics analysis of the single-fiber pull-out test and the microbond test including the effects of friction and thermal stresses," in Proceedings of the 16th Annual Technical Conference, pp. 1-12, American Society for Composites, Blacksburg, Va, USA, September 2001.

[19] W. Kim and N. Kim, "Reduction of residual stress in composite patch," in Proceedings of the 13th International Conference on Composite Materials, pp. 1-8, Beijing, China, June 2001.

[20] K. Renner, J. Móczó, P. Suba, and B. Pukánszky, "Micromechanical deformations in PP/lignocellulosic filler composites: effect of matrix properties," Composites Science and Technology, vol. 70, no. 7, pp. 1141-1147, 2010.

[21] D. Ratna, "Modification of epoxy resins for improvement of adhesion: a critical review," Journal of Adhesion Science and Technology, vol. 17, no. 12, pp. 1655-1668, 2003.

[22] M. Tehrani, M. Al-Haik, H. Garmestani, and D. Li, "Effect of moderate magnetic annealing on the microstructure, quasistatic, and viscoelastic mechanical behavior of a structural epoxy," Journal of Engineering Materials and Technology, vol. 134, no. 1, Article ID 010907, pp. 1-10, 2012.

[23] R. L. Sierakowski, I. Y. Telichev, and O. I. Zhupanska, "A study of composite strengthening through application of an electric field," in Proceedings of the ASME International Mechanical Engineering Congress and Exposition (IMECE '06), November 2006. 
[24] O. I. Zhupanska and R. L. Sierakowski, "Effects of an electromagnetic field on the mechanical response of composites," Journal of Composite Materials, vol. 41, no. 5, pp. 633-652, 2007.

[25] M. N. Ajour, The effect of high voltage fields on epoxy laminates [Ph.D. dissertation], Department of Engineering, University of Leicester, 2003

[26] Y. Chen and C.-Y. Shew, "Conformational behavior of polar polymer models under electric fields," Chemical Physics Letters, vol. 378, no. 1-2, pp. 142-147, 2003.

[27] M. S. Mehata, K. Awasthi, T. Iimori, and N. Ohta, "Electric field effects on state energy and molecular orientation of 2hydroxyquinoline in solid polymer films," Journal of Photochemistry and Photobiology A: Chemistry, vol. 204, no. 1, pp. 3945, 2009.

[28] L. Lavielle, K. Nakajima, and J. Schultz, "Influence of an electric field on polar-group orientation and adhesion at poly(ethylene terephthalate) surfaces," Journal of Applied Polymer Science, vol. 46, no. 6, pp. 1045-1050, 1992.

[29] G. A. Puchkovskaya, Y. A. Reznikov, A. A. Yakubov, O. V. Yaroshchuk, and A. V. Glushchenko, "Transformation of hydrogen bonding of a liquid crystal-aerosil system under the influence of an electric field," Journal of Molecular Structure, vol. 381, no. 1-3, pp. 133-139, 1996.

[30] D. Rai, A. D. Kulkarni, S. P. Gejji, and R. K. Pathak, "Is high electric field capable of selectively inducing a covalent-like bond between polar and non-polar molecular species?" Theoretical Chemistry Accounts, vol. 123, no. 5-6, pp. 501-511, 2009.

[31] S. Wen and D. D. L. Chung, "Electric polarization in carbon fiber-reinforced cement," Cement and Concrete Research, vol. 31, no. 1, pp. 141-147, 2001.

[32] I. B. Amor, Z. Ghallabi, H. Kaddami, M. Raihane, M. Arous, and A. Kallel, "Experimental study of relaxation process in unidirectional (epoxy/palm tree fiber) composite," Journal of Molecular Liquids, vol. 154, no. 2-3, pp. 61-68, 2010.

[33] J. Duan, J. Zhang, and P. Jiang, "Effect of external electric field on morphologies and properties of the cured epoxy and epoxy/acrylate systems," Journal of Applied Polymer Science, vol. 125, no. 2, pp. 902-914, 2012.

[34] L. Núñez-Regueira, S. Gómez-Barreiro, and C. A. GraciaFernández, "Study of the influence of isomerism on the curing properties of the epoxy system DGEBA $(n=0) / 1,2 \mathrm{DCH}$ by DEA and MDSC," Journal of Thermal Analysis and Calorimetry, vol. 82, no. 3, pp. 797-801, 2005.

[35] A. Shiota and C. K. Ober, "Orientation of liquid crystalline epoxides under ac electric fields," Macromolecules, vol. 30, no. 15, pp. 4278-4287, 1997.

[36] R. Meir, H. Chen, W. Lai, and S. Shaik, "Oriented electric fields accelerate diels-alder reactions and control the endo/exo selectivity," ChemPhysChem, vol. 11, no. 1, pp. 301-310, 2010.

[37] C. A. Genge, The Effect of Alternating Electrical Fields on the Polymerization of Styrene, McGill University, Montreal, Canada, 1947.

[38] R. Johnson, H. Chicago, W. Young, and T. Findley, "Polymerization inhibition in oxirane containing fatty acid esters," US Patent No. 3,230,189, 1966.

[39] G. Guven, Shear band propagation in cross linked epoxies [Thesis], Polymer Science and Engineering, Lehigh University, 1998.

[40] T. M. Prozonic, The effect of epoxy network structure on toughenability [Thesis], Polymer Science and Engineering, Lehigh University, 2012.
[41] B. Fahlman, Material Chemistry, Springer Science+Business Media, New York, NY, USA, 2nd edition, 2011.

[42] W. Liu, J. Tang, B. Huang, and Y. Du, "Electric-field-enhanced crystallization of amorphous $\mathrm{Fe}_{86} \mathrm{Zr}_{7} \mathrm{~B}_{6} \mathrm{Cu}_{1}$ alloy," Journal of Alloys and Compounds, vol. 420, no. 1-2, pp. 171-174, 2006.

[43] K. V. Saban and G. Varghese, "Thermodynamics of crystal nucleation in drops, hanging or sitting in an external electric field," Indian Journal of Pure and Applied Physics, vol. 40, no. 8, pp. 552-555, 2002.

[44] K. V. Saban, J. Thomas, P. A. Varughese, and G. Varghese, "Thermodynamics of crystal nucleation in an external electric field," Crystal Research and Technology, vol. 37, no. 11, pp. 11881199, 2002.

[45] Y. Li and M. R. Kessler, "Liquid crystalline epoxy resin based on biphenyl mesogen: effect of magnetic field orientation during cure," Polymer, vol. 54, no. 21, pp. 5741-5746, 2013.

[46] M. Tehrani, M. Al-Haik, H. Garmestani, and D. Li, "Effect of moderate magnetic annealing on the microstructure, quasistatic, and viscoelastic mechanical behavior of a structural epoxy," Journal of Engineering Materials and Technology, vol. 134, no. 1, Article ID 010907, 2012.

[47] H. Z. Akbaş, H. Durmuş, and G. Ahmetli, "Dielectric properties of cured epoxy with teta," Ozean Journal of Applied Science, vol. 2, no. 4, pp. 443-449, 2009.

[48] J. P. Eloundou, "Dipolar relaxations in an epoxy-amine system," European Polymer Journal, vol. 38, no. 3, pp. 431-438, 2002.

[49] M. S. Al-Haik, H. Garmestani, D. S. Li et al., "Mechanical properties of magnetically oriented epoxy," Journal of Polymer Science Part B: Polymer Physics, vol. 42, no. 9, pp. 1586-1600, 2004.

[50] P. Huyskens, L. Sobczyk, and I. Majerz, "On a hard/soft hydrogen bond interaction," Journal of Molecular Structure, vol. 615, no. 1-3, pp. 61-72, 2002.

[51] B. Miroslaw, A. E. Koziol, A. Bielenica, K. Dziuba, and M. Struga, "Substituent effect on supramolecular motifs in series of succinimide polycyclic keto derivatives-spectroscopic, theoretical and crystallographic studies," Journal of Molecular Structure, vol. 1074, pp. 695-702, 2014.

[52] C.-C. Liao, C.-C. Wang, K.-C. Shih, and C.-Y. Chen, "Electrospinning fabrication of partially crystalline bisphenol A polycarbonate nanofibers: effects on conformation, crystallinity, and mechanical properties," European Polymer Journal, vol. 47, no. 5, pp. 911-924, 2011.

[53] B. Bolasodun, O. Rufai, and S. Durowaiye, "Infrared studies of curing of araldite DLS 772/4 4' DDS and araldite LY 5052/4 $4^{\prime}$ DDS epoxy systems using conventional and microwave energy," International Journal of Engineering Science, vol. 3, no. 1, pp. 1123, 2014.

[54] J. Coates, "Interpretation of infrared spectra, a practical approach," in Encyclopedia of Analytical Chemistry, R. Meyers, Ed., pp. 10815-10837, John Wiley \& Sons, Chichester, UK, 2000.

[55] A. Boukenter, E. Duval, and H. M. Rosenberg, "Raman scattering in amorphous and crystalline materials: a study of epoxy resin and DGEBA," Journal of Physics C: Solid State Physics, vol. 21, no. 15 , pp. 541-547, 1988.

[56] D. Freude, "Molecules in electric and magnetic fields," in Molecular Physics, pp. 1-26, 2005.

[57] M. T. Darestani, T. C. Chilcott, and H. G. L. Coster, "Changing the microstructure of membranes using intense electric fields: dielectric strength studies," Journal of Membrane Science, vol. 452, pp. 367-378, 2014. 
[58] L. Xu and L. T. Drzal, "Improvement of adhesion between vinyl ester resin and carbon fibers," in Proceedings of the 13th International Conference on Composite Materials (ICCM '01), pp. 1-10, Beijing, China, September 2001.

[59] R. A. Pearson, A. F. Yee, D. Building, and A. Arbor, "Toughening mechanisms in elastomer-modified epoxies," Journal of Materials Science, vol. 24, pp. 2571-2580, 1989.

[60] H. Lützen, T. M. Gesing, and A. Hartwig, "Nucleation as a new concept for morphology adjustment of crystalline thermosetting epoxy polymers," Reactive and Functional Polymers, vol. 73, no. 8, pp. 1038-1045, 2013.

[61] F. J. Guild, A. J. Kinloch, and A. C. Taylor, "Particle cavitation in rubber toughened epoxies: the role of particle size," Journal of Materials Science, vol. 45, no. 14, pp. 3882-3894, 2010.

[62] J. K. Kim and R. E. Robertson, "Toughening of thermoset polymers by rigid crystalline particles," Journal of Materials Science, vol. 27, no. 1, pp. 161-174, 1992.

[63] M. Aufray and A. André Roche, "Epoxy-amine/metal interphases: influences from sharp needle-like crystal formation," International Journal of Adhesion and Adhesives, vol. 27, no. 5, pp. 387-393, 2007.

[64] B. S. Hsiao and E. J. Chen, "Transcrystalline interphase in advanced polymer composites," in Controlled Interphases in Composite Materials: Proceedings of the Third International Conference on Composite Interfaces (ICCI-III) held on May 2124, 1990 in Cleveland, Ohio, USA, pp. 613-622, Springer, Cham, Switzerland, 1990.

[65] J. Song, A. Bringuier, S. Kobayashi, A. M. Baker, and C. W. Macosko, "Adhesion between polyethylenes and different types of polypropylenes," Polymer Journal, vol. 44, no. 9, pp. 939-945, 2012.

[66] L. T. Drzal, "The effect of polymeric matrix mechanical properties on the fiber-matrix interfacial shear strength," Materials Science and Engineering: A, vol. 126, no. 1-2, pp. 289-293, 1990.

[67] D. Nwabunma and T. Kyu, Polyolefin Composites, John Wiley \& Sons, New Jersey, NJ, USA, 2008.

[68] K. P. Pang and J. K. Gillham, "Anomalous behavior of cured epoxy resins: density at room temperature versus time and temperature of cure," Journal of Applied Polymer Science, vol. 37, no. 7, pp. 1969-1991, 1989.

[69] T. H. Chiang and T.-E. Hsieh, "A study of monomer's effect on adhesion strength of UV-curable resins," International Journal of Adhesion and Adhesives, vol. 26, no. 7, pp. 520-531, 2006.

[70] M. Zarrelli, A. A. Skordos, and I. K. Partridge, "Investigation of cure induced shrinkage in unreinforced epoxy resin," Plastics, Rubber and Composites, vol. 31, no. 9, pp. 377-384, 2002. 

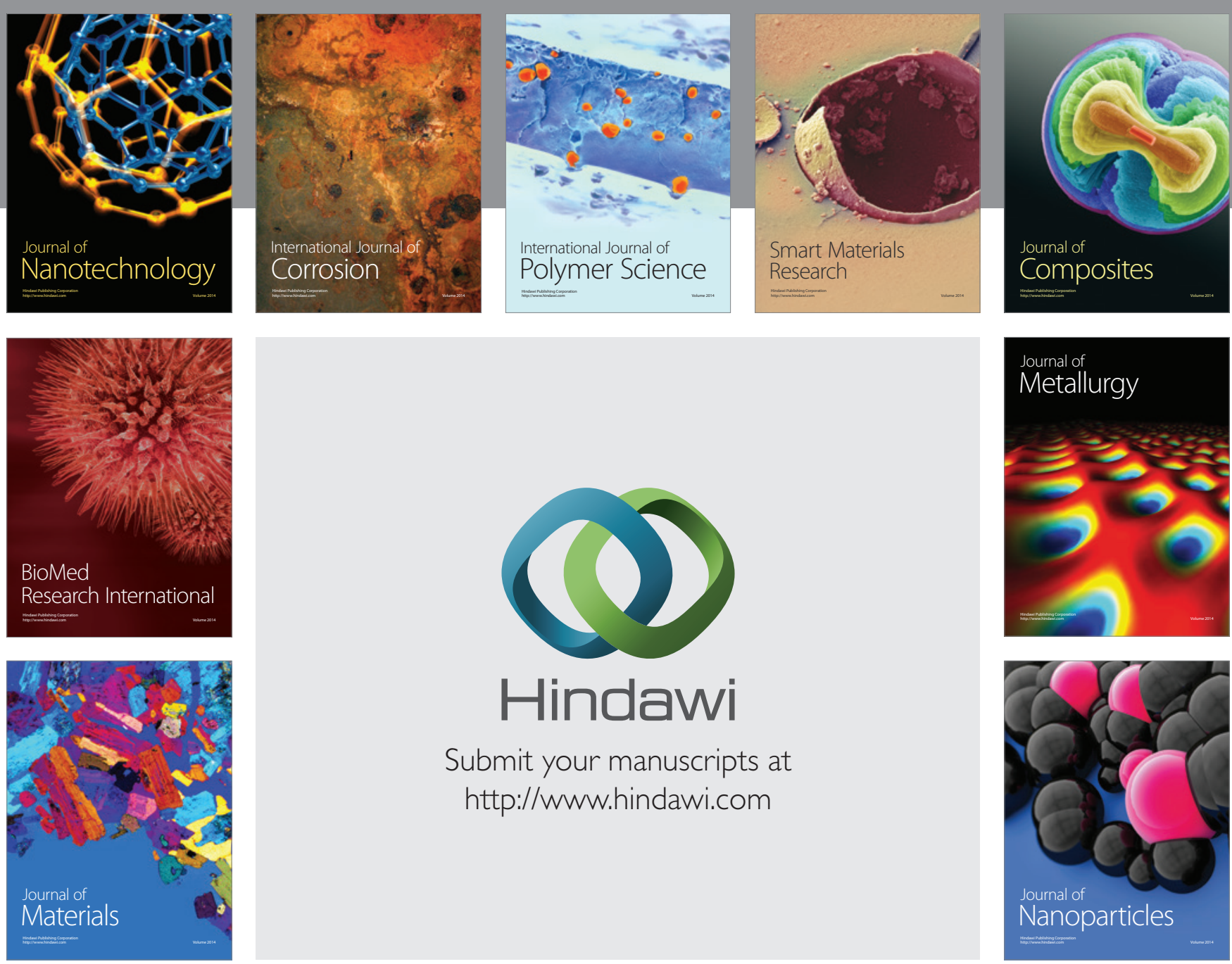

Submit your manuscripts at http://www.hindawi.com
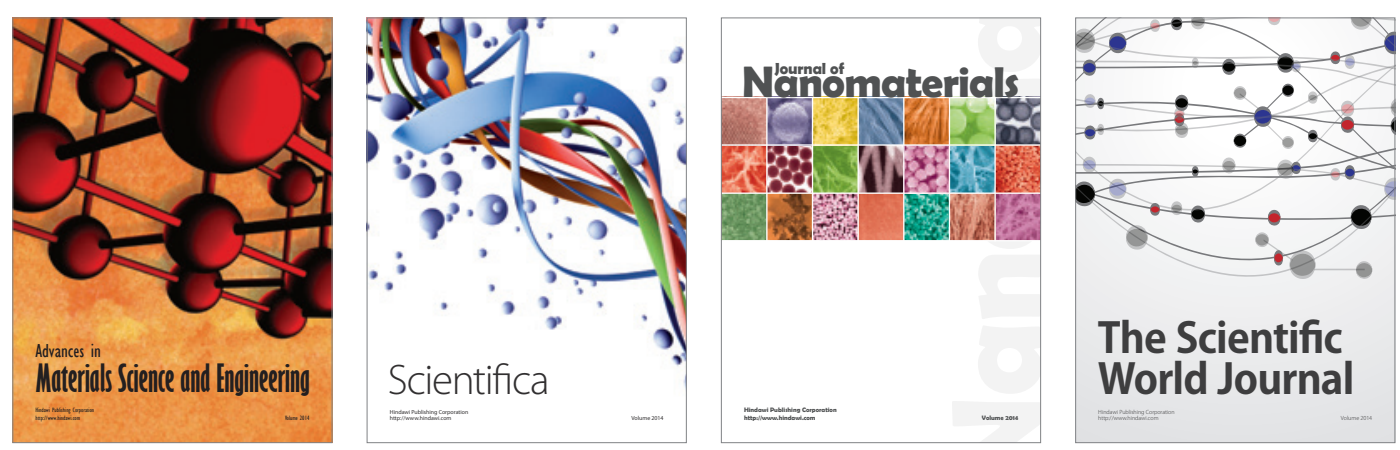

\section{The Scientific World Journal}
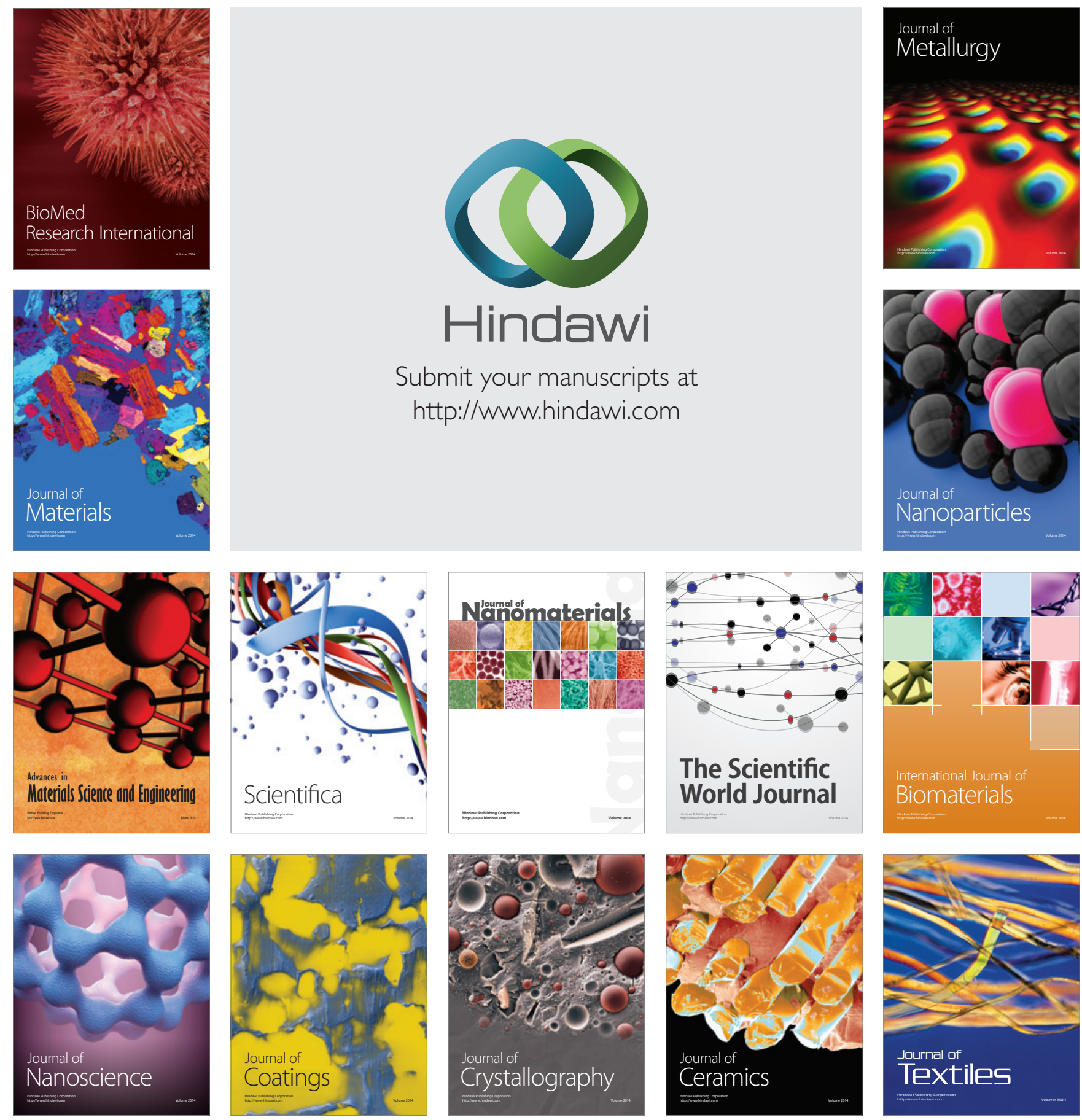